09

\title{
Преобразование мод в гибридных волноводных структурах на основе ниобата лития для согласования со стандартным одномодовым оптическим волокном
}

\author{
(C) М.В. Парфеенов, ${ }^{1,2}$ П.М. Агрузов, ${ }^{1}$ И.В. Ильичев, ${ }^{1}$ А.А. Усикова, ${ }^{1}$ А.В. Шамрай ${ }^{1}$ \\ ${ }^{1}$ Физико-технический институт им. А.Ф. Иоффре РАН, \\ 194021 Санкт-Петербург, Россия \\ ${ }^{2}$ Санкт-Петербургский политехнический университет Петра Великого, \\ 195251 Санкт-Петербург, Россия \\ E-mail: mvparfenov@mail.ioffe.ru
}

Поступило в Редакцию 20 июля 2021 г.

В окончательной редакции 4 октября 2021 г.

Принято к публикации 5 октября 2021 г.

\begin{abstract}
Предложена конфигурация гибридной волноводной структуры, обеспечивающей эффективное преобразование моды градиентного титан-диффузного оптического волновода, согласованного с одномодовым оптическим волокном, в моду гибридного гребенчатого волновода с малым размером модового пятна. Были рассмотрены два наиболее перспективных материала для формирования гибридных волноводов: кремний и диоксид титана. Теоретический анализ показал, что эффективность преобразования выше 99\% достижима для структур на основе диоксида титана с технологическими допусками, соответствующими контактной фотолитографии.
\end{abstract}

Ключевые слова: интегральная оптика, волновод, ниобат лития, тейпер, кремний, диоксид титана.

DOI: $10.21883 / J T F .2022 .01 .51860 .220-21$

\section{Введение}

Ниобат лития $\left(\mathrm{LiNbO}_{3}\right)$ на сегодняшний день является одним из основных материалов для создания сверхширокополосных оптических модуляторов [1]. Особый интерес представляют технологии тонкопленочных гибридных волноводов [2], которые благодаря высокой числовой апертуре и малому размеру модового пятна позволяют изготавливать интегрально-оптические модуляторы с полуволновым напряжением менее $1 \mathrm{~V}$ и частотной полосой более $10 \mathrm{GHz}$ [3]. Одной из главных технических проблем, связанных с применением модуляторов на основе гибридных тонкопленочных волноводов, является реализация ввода/вывода оптического излучения и согласование интегрально-оптических схем со стандартным одномодовым оптическим волокном. В настоящее время наиболее широко используются два подхода к решению данной проблемы: использование поверхностных дифракционных решеток [4] и специального линзованного оптического волокна вместе с волноводным преобразователем на основе тейпера (волноводного элемента с плавным изменением сечения) [5-7]. Оба подхода требуют очень высокой точности юстировки, причем между торцом волокна и элементом ввода существует воздушный зазор, что может приводить к интерференционным эффектам при переотражениях и делает конструкцию стыковочных модулей восприимчивой к внешним воздействиям, таким как изменение температуры.
Для стандартных градиентных волноводов на подложках ниобата лития, изготовленных диффузионными методами (методом термической диффузии или методом протонного обмена), хорошо отработана техника стыковки с одномодовым оптическим волокном, использующая отполированные стыковочные модули с вклеенным стандартным одномодовым волокном [8], которые приклеиваются к торцу интегрально-оптической схемы. Хорошее согласование мод оптического волокна и волновода обеспечивает низкие оптические потери менее $0.5 \mathrm{~dB}$ на стыковку, а монолитное исполнение обеспечивает высокую механическую прочность и слабое влияние изменений внешних условий.

Мы предлагаем использовать в области стыковки с оптическим волокном стандартные волноводы, изготовленные диффузионным методом, на поверхности которых изготавливается гибридная волноводная структура для преобразования моды диффузионного волновода с низкой числовой апертурой, согласованной со стандартным одномодовым телекоммуникационным волокном, в моду с высокой числовой апертурой и малым размером модового пятна, характерную для тонкопленочных гибридных волноводов на ниобате лития. Идея использования гибридных волноводных структур для преобразования мод была предложена нами ранее для повышения эффективности волноводного детектора одиночных фотонов [9], но без детального количественного анализа. Цель настоящей работы - провести теоретический анализ преобразования мод и определить оптимальную 


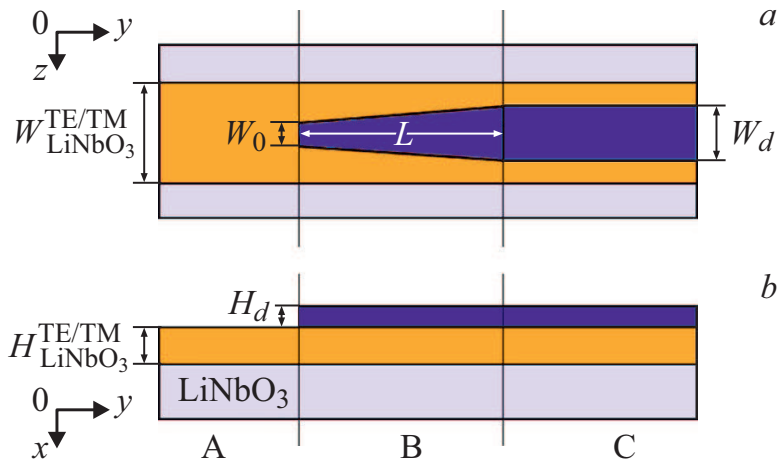

Рис. 1. Топология гибридного волноводного преобразователя мод: $a-$ вид сверху, $b-$ вид сбоку.

конфигурацию и материалы для изготовления волноводного гибридного модового преобразователя.

\section{1. Модель преобразователя}

Конфигурация модового преобразователя, предлагаемого для рассмотрения, показана на рис. 1. На подложке ниобата лития $x$-среза вдоль направления кристаллографической оси $y$ сформирован канальный титан-диффузный волновод. Данная ориентация наиболее широко применяется в электрооптических модуляторах [1], работающих с линейно поляризованной вдоль оси $z$ квази ТЕ-модой. Поскольку волноводы обеих широко применяемых диффузионных технологий (термической диффузии титана и протонного обмена) сходны по характеристикам (размерам, профилю показателя преломления, форме мод), но в протонно-обменном волноводе не поддерживается существование ТМ-мод [10], для наиболее полного рассмотрения модели преобразователя мод выбран именно волновод, изготовленный методом термической диффузии.

Секция $A$ преобразователя (рис. 1) представляет собой участок с прямым титан-диффузным волноводом, секция $C-$ участок с гибридным волноводом на основе полоски материала с высоким показателем преломления (выше, чем у ниобата лития), расположенной над титан-диффузным волноводом. В структуре волноводного элемента, расположенного между ними в секции $B$, непосредственно происходит адиабатическое преобразование мод.

Появляясь на пути оптической волны в секции $B$, диэлектрическая полоска с высоким коэффициентом преломления изменяет пространственное распределение интенсивности мод. Волноводная мода титан-диффузного волновода по мере увеличения поперечных размеров полоски преобразовывается в моду, локализованную в полоске с высоким показателем преломления и имеющую высокую числовую апертуру моду гибридной волноводной структуры.
В качестве материалов для гибридных тонкопленочных волноводных структур были рассмотрены: диоксид титана $\left(n_{\mathrm{TiO}_{2}}=2.31[11]\right)$ и кремний $\left(n_{\mathrm{Si}}=3.48[12]\right)$. Данные материалы подтвердили эффективность своего использования для создания гибридных волноводов на подложках ниобата лития [2].

\section{2. Численный анализ}

Первоначально был проведен модовый анализ гибридных волноводов на выходе модового преобразователя (в секции $C$ на рис. 1). Он был проведен при помощи моделирования методом конечных элементов в программном пакете COMSOL на телекоммуникационной длине волны $\lambda=1550 \mathrm{~nm}$.

Для удобства проведения расчетов и большей наглядности анализа результатов модель преобразователя была упрощена: градиентный профиль распределения показателя преломления титан-диффузного волновода был заменен ступенчатым профилем с эквивалентным размером модового пятна [13]; показатель преломления подложки для квази ТЕ-поляризации был принят равным $n_{s}^{e}=2.140$, показатель преломления волноводного канала $n_{w}^{e}=2.145$, эффективные высота и ширина волноведущего канала $H_{\mathrm{LiNbO}_{3}}^{\mathrm{TE}}=4.5 \mu \mathrm{m}$ и $W_{\mathrm{LiNbO}_{3}}^{\mathrm{TE}}=8.0 \mu \mathrm{m}$ соответственно. Для ортогональной (квази ТМ) поляризации параметры отличались: $n_{s}^{o}=2.210, n_{w}^{o}=2.212$, $H_{\mathrm{LiNbO}_{3}}^{\mathrm{TE}}=7.5 \mu \mathrm{m}$ и $W_{\mathrm{LiNbO}_{3}}^{\mathrm{TE}}=10.5 \mu \mathrm{m}$, из-за анизотропии кристаллической подложки [13].

Было выяснено, что мода $\mathrm{TE}_{\mathrm{loc}}$, локализованная в полоске с высоким показателем преломления, может распространяться по гибридному волноводу при различных соотношениях между $H_{d}$ и $W_{d}$ (рис. 2). Для кремния, имеющего больший показатель преломления по сравнению с диоксидом титана, локализованная мода возникает при меньших размерах полоски, и соответственно

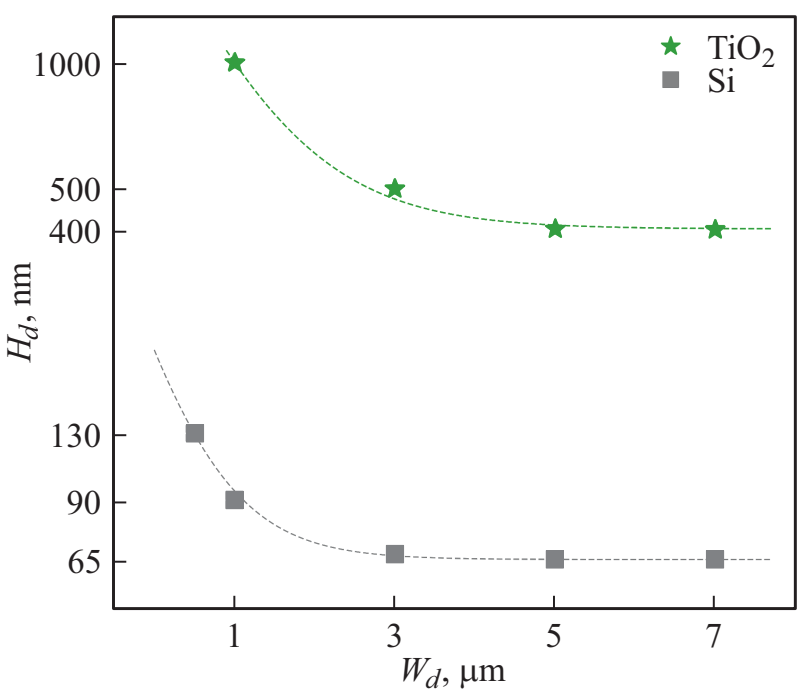

Рис. 2. Условия существования $\mathrm{TE}_{\mathrm{loc}}-\mathrm{Mоды,} \mathrm{локализованной} \mathrm{в}$ полоске с высоким коэффициентом преломления. 

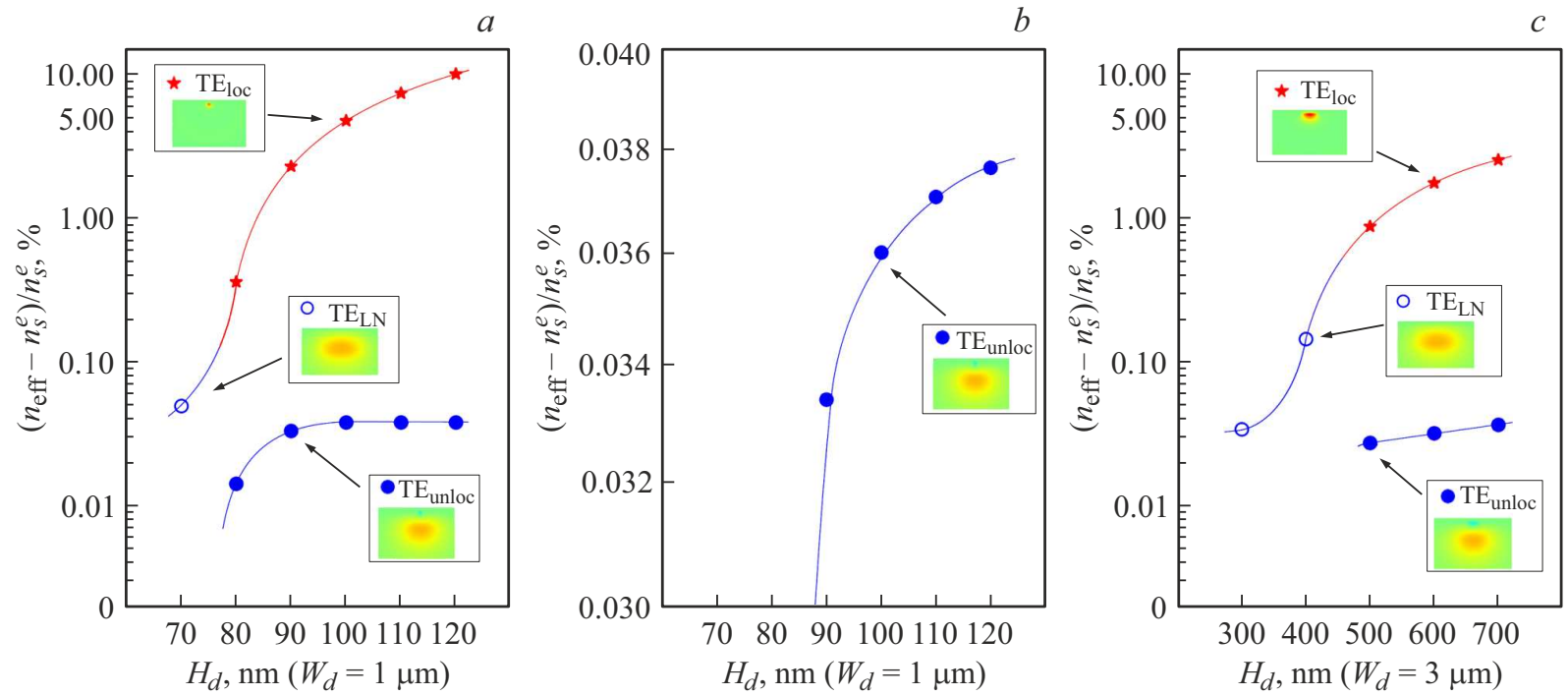

Pис. 3. Зависимость эффективных показателей преломления гибридных квази ТЕ-мод от высоты полоски $H_{d}: a, b-$ для кремния при ширине полоски $W_{d}=1 \mu \mathrm{m}, c$ - для диоксида титана при фиксированной ширине $W_{d}=3 \mu \mathrm{m}$. Графические вставки иллюстрируют профили распределения электрического поля мод.
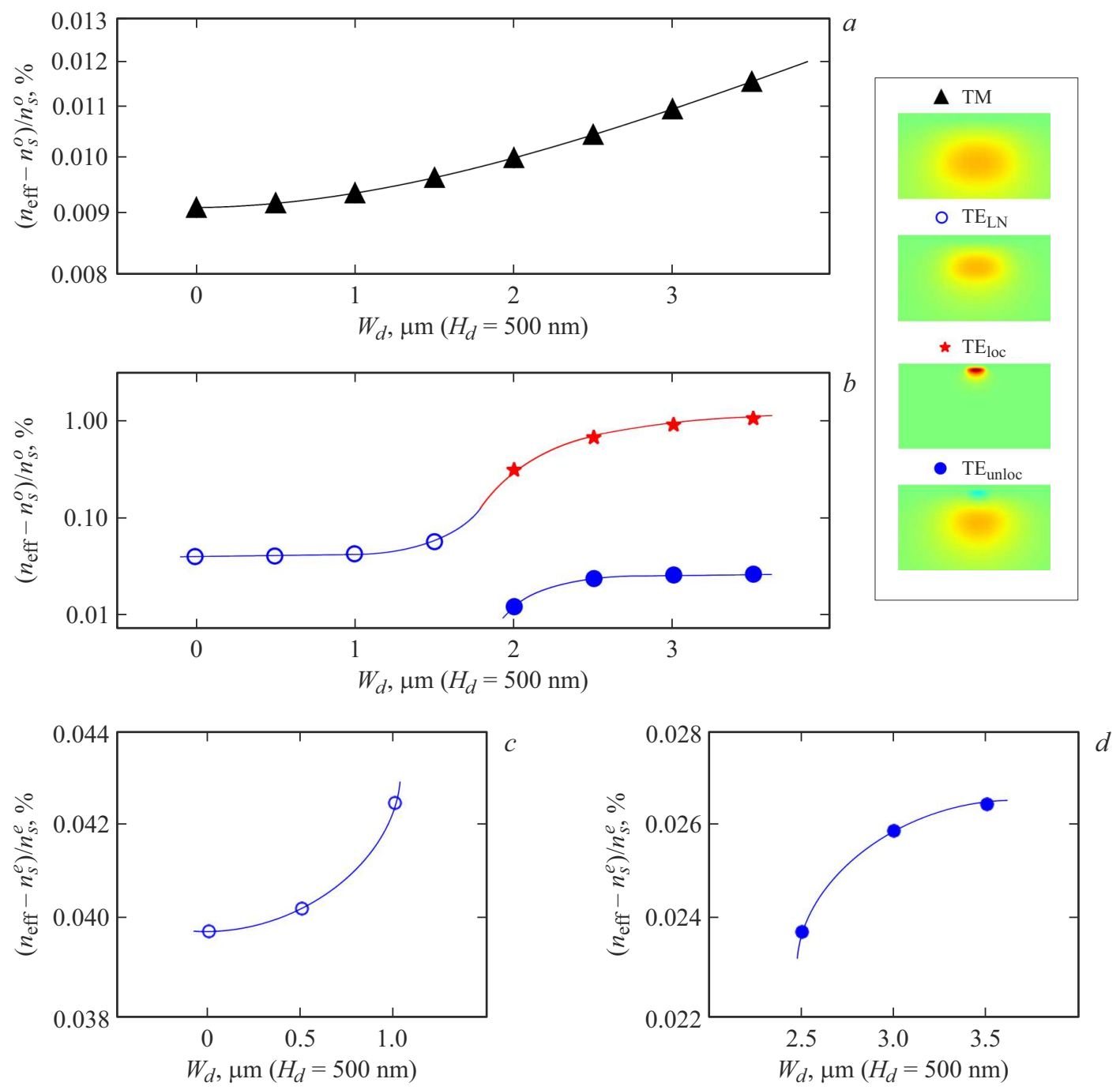

Рис. 4. Эффективный показатель преломления волноводных мод в зависимости от ширины тейпера на основе диоксида титана $\mathrm{W}$ при фиксированной высоте $H_{d}=500 \mathrm{~nm}$ для ТМ-моды $(a)$ и ТЕ-мод $(b-d)$. Графические вставки иллюстрируют профили распределения электрического поля мод для разных поперечных сечений тейпера. 
имеет меньшие поперечные размеры и более высокую числовую апертуру. Однако диоксид титана предпочтительнее с технологической точки зрения, поскольку большие размеры полоски диоксида титана ослабляют требования к точности технологического оборудования, и это позволяет изготавливать преобразователь мод с использованием методов контактной фотолитографии. Отметим, что даже использование диоксида титана позволяет уменьшить эффективный диаметр моды более чем в три раза, и повысить локальную интенсивность оптического излучения и эффективность электрооптического управления более чем на порядок.

На рис. 3 представлены теоретические зависимости эффективных показателей преломления волноводных мод гибридной структуры, нормированных на показатель преломления подложки, от высоты полоски при фиксированной ширине $W_{d}=3 \mu \mathrm{m}$ для диоксида титана и $W_{d}=1 \mu \mathrm{m}$ для кремния. Большая разница эффективных показателей преломления и различие между полями этих мод приводит к тому, что локализованная мода слабо взаимодействует с фундаментальной модой титан-диффузного волновода, поэтому для эффективной перекачки излучения и необходимо специальное устройство на основе тейпера - волноведущего слоя с плавным изменением ширины (рис. 1).

Было проведено детальное исследование распространения света в преобразователе мод, выполненном на основе тейпера. Такой преобразователь мод должен трансформировать моду волновода адиабатически. Гибридную волноводную структуру на основе диоксида титана, как уже было отмечено ранее, можно изготовить с меньшими требованиями к точности размеров волноводного элементов методами контактной фотолитографии, поэтому анализ был проведен для тейпера на основе диоксида титана. Высота полоски диоксида титана $H_{d}=500 \mathrm{~nm}$ и ширина тейпера на выходе $W_{d}=3 \mu \mathrm{m}$ были выбраны на основе анализа условий существования локализованной моды (рис. 2). Начальная ширина $W_{0}=1 \mu \mathrm{m}$ и длина $L=3400 \mu \mathrm{m}$ тейпера были выбраны для обеспечения адиабатического преобразования мод. Результаты анализа гибридных мод тейпера, представленные на рис. 4, показали, что ТМ-мода титан-диффузного волновода не чувствует наличие гибридного волноведущего слоя, ее эффективный показатель преломления не изменяется и преобразования квази ТМ-моды на тейпере не происходит. Для ТЕ-моды преобразование моды титан-диффузного волновода в локализованную моду гибридной структуры происходит при плавном увеличении ширины тейпера от 1.5 до $2 \mu \mathrm{m}$. Дисперсионные кривые для ортогонально поляризованных ТЕ- и ТМ-мод расположены далеко друг от друга благодаря сильно различающимся значениям $n_{s}^{e}, n_{s}^{o}$ и слабым отклонениям от них эффективных показателей преломления мод, что обеспечивает отсутствие поляризационных преобразований.

Для анализа процесса распространения света по тейперу, подтверждения адиабатического режима работы

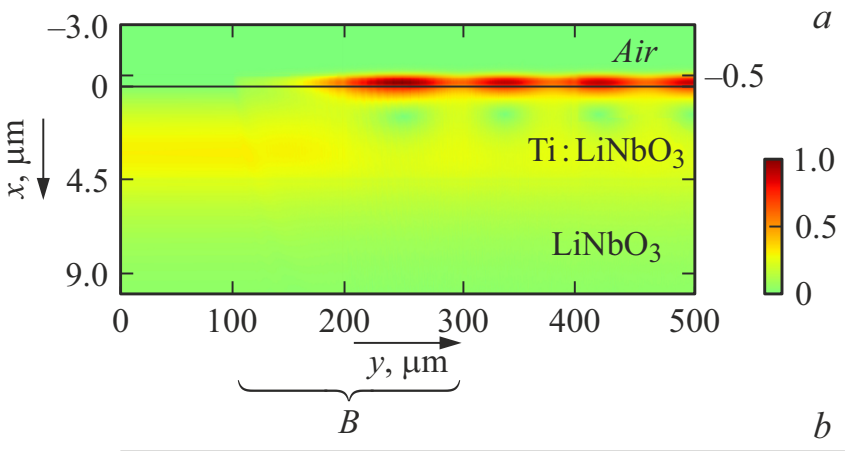

$a$

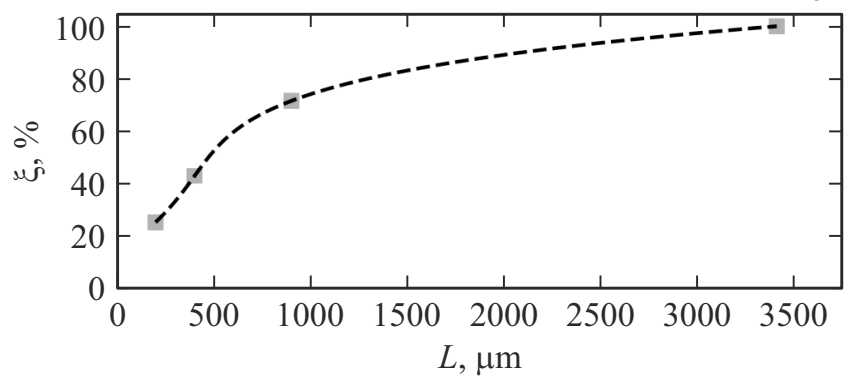

Рис. 5. Результаты анализа распространения света через тейпер на основе диоксида титана $\left(H_{d}=500 \mathrm{~nm}, W_{0}=1 \mu \mathrm{m}\right.$, $\left.W_{d}=3 \mu \mathrm{m}\right): a$ - пространственное распределение интенсивности для тейпера длиной $L=200 \mu \mathrm{m}, b-$ зависимость эффективности преобразования мод в тейпере от его длины $L$.

преобразователя мод и количественной оценки эффективности преобразования в локализованную моду гибридного волновода был использован численный метод распространения лучей (ВРМ) [14]. В качестве входного сигнала была использована фундаментальная ТЕ-мода титан-диффузного волновода. Конечная эффективность преобразования мод, зависящая от длины тейпера, приводит к тому, что часть оптической мощности продолжает распространяться в титан-диффузном волноводе. Это проявляется в виде интерференционной картины распространяющихся мод, наблюдаемой на результатах моделирования ВРМ методом (рис. 5,a). На основе контраста интерференционной картины была рассчитана эффективность преобразования мод на тейпере как отношение мощности моды локализованной TEloc к суммарной мощности мод на выходе тейпера: $\xi=\frac{P_{\mathrm{Te}_{\mathrm{loc}}}}{P_{\mathrm{Te}_{\mathrm{loc}}}+P_{\mathrm{Te}_{\mathrm{unloc}}}}$ (рис. 5,b). При длине тейпера $L=3400 \mu \mathrm{m}$ эффективность преобразования составила более $99 \%$, а режим работы тейпера близок к адиабатическому.

\section{Заключение}

По результатам проведенного теоретического анализа было показано, что гибридные волноводные структуры могут быть эффективно использованы для преобразования мод стандартных градиентных волноводов на подложках ниобата лития в локализованные моды гибридных гребенчатых волноводов. Диоксид титана и 
кремний были рассмотрены как перспективные материалы для изготовления преобразователей мод. Показано, что модовый преобразователь в виде тейпера на основе диоксида титана обеспечивает эффективность преобразования свыше $99 \%$ и отсутствие поляризационных преобразований, что особенно важно для эффективной электрооптической модуляции. Результаты работы могут быть использованы для создания технологии стыковки гибридных тонкопленочных интегральных схем со стандартным одномодовым телекоммуникационным волокном.

\section{Финансирование работы}

Исследование выполнено за счет гранта Российского научного фонда (проект № 19-19-00511).

\section{Конфликт интересов}

Авторы заявляют, что у них нет конфликта интересов.

\section{Список литературы}

[1] В.М. Петров, П.М. Агрузов, В.В. Лебедев, И.В. Ильичев, А.В. Шамрай. УФН, 191, 760 (2021). DOI: $10.3367 / \mathrm{UFNr} .2020 .11 .038871$

[2] Y. Jia, L. Wang, F. Chen. Appl. Phys. Rev., 8, 011307 (2021). DOI: $10.1063 / 5.0037771$

[3] M. Zhang, C. Wang, P. Kharel, D. Zhu, M. Lončar. Optica, 8 (5), 652 (2021). DOI: 10.1364/OPTICA.415762

[4] I. Krasnokutska, R.J. Chapman, J.J. Tambasco, A. Peruzzo. Opt. Express, 27 (13), 17681 (2019). DOI: $10.1364 /$ OE.27.017681

[5] C. Hu, A. Pan, T. Li, X. Wang, Y. Liu, S. Tao, C. Zeng, J. Xia. Opt. Express., 29 (4), 5397 (2021). DOI: 10.1364/OE.416492

[6] L. He, M. Zhang, A. Shams-Ansari, R. Zhu, C. Wang, L. Marko. Opt. Lett., 44 (9), 2314 (2019). DOI: $10.1364 /$ OL.44.002314

[7] P. Ying, H. Tan, J. Zhang, M. He, M. Xu, X. Liu, R. Ge, Y. Zhu, C. Liu, X. Cai. Opt. Lett., 46 (6), 1478 (2021). DOI: $10.1364 /$ OL.418996

[8] V. Ramaswamy, R.C. Alferness, M. Divino. Electron. Lett. 18 (1), 30 (1982). DOI: 10.1049/el:19820022

[9] М.В. Парфенов, А.В. Шамрай. Письма в ЖТФ, 46 (16), 39 (2020). DOI: 10.21883/PJTF.2020.16.49853.18344

[10] M. Bazzan, C. Sada. Appl. Phys. Rev., 2 (4), 040603 (2015). DOI: $10.1063 / 1.4931601$

[11] X. Guan, H. Hu, L.K. Oxenløwe, L.H. Frandsen. Opt. Express, 26 (2), 1055 (2018). DOI: 10.1364/OE.26.001055

[12] H.H. Li. J. Phys. Chem. Ref. Data, 9, 561 (1980). DOI: $10.1063 / 1.555624$

[13] M. Parfenov, P. Agruzov, I. Ilichev, A. Shamray. J. Phys.: Conf. Ser., 741 (1), 012141 (2016). DOI: $10.1088 / 1742-6596 / 741 / 1 / 012141$

[14] J. Van Roey, J. van der Donk, P.E. Lagasse. J. Opt. Soc. Am., 71 (7), 803 (1981). DOI: 10.1364/JOSA.71.000803 